OPEN ACCESS

Edited by:

Yury Y. Shtyrov,

Aarhus University, Denmark

Reviewed by:

Karolina Krzyżanowska, University of Amsterdam, Netherlands

Mailin Antomo,

University of Göttingen, Germany

Laia Mayol,

Pompeu Fabra University, Spain Jacqueline Visconti,

University of Genoa, Italy

*Correspondence:

Mingya Liu

mingya.liu@hu-berlin.de

Specialty section:

This article was submitted to

Language Sciences,

a section of the journal

Frontiers in Psychology

Received: 13 November 2020

Accepted: 23 June 2021

Published: 10 August 2021

Citation:

Liu M (2021) Processing Non-at-Issue Meanings of Conditional Connectives: The wenn/falls Contrast in German

Front. Psychol. 12:629177. doi: 10.3389/fpsyg.2021.629177

\section{Processing Non-at-Issue Meanings of Conditional Connectives: The wenn/falls Contrast in German}

\author{
Mingya Liu* \\ Department of English and American Studies, Humboldt University of Berlin, Berlin, Germany
}

Logical connectives in natural language pose challenges to truth-conditional semantics due to pragmatics and gradience in their meaning. This paper reports on a case study of the conditional connectives (CCs) wenn/falls 'if/when, if/in case' in German. Using distributional evidence, I argue that wenn and falls differ in lexical pragmatics: They express different degrees of speaker commitment (i.e., credence) toward the modified antecedent proposition at the non-at-issue dimension. This contrast can be modeled using the speaker commitment scale (Giannakidou and Mari, 2016), i.e., More committed $<$ WENN p, FALLS p $>$ Less committed. Four experiments are reported which tested the wenn/falls contrast, as well as the summary of an additional one from Liu (2019). Experiment 1 tested the naturalness of sentences containing the CCs (wenn or falls) and conditional antecedents with varying degrees of likelihood (very likely/likely/unlikely). The starting prediction was that falls might be degraded in combination with very likely and likely events in comparison to the other conditions, which was not borne out. Experiment 2 used the forced lexical choice paradigm, testing the choice between wenn and falls in the doxastic agent's conditional thought, depending on their belief or disbelief in the antecedent. The finding was that subjects chose falls significantly more often than wenn in the disbelief-context, and vice versa in the belief-context. Experiment 3 tested the naturalness of sentences with CCs and an additional relative clause conveying the speaker's belief or disbelief in the antecedent. An interaction was found: While in the belief-context, wenn was rated more natural than falls, the reverse pattern was found in the disbelief-context. While the results are mixed, the combination of the findings in Experiment 2, Experiment 3 and that of Experiment $4 \mathrm{a}$ from Liu (2019) that falls led to lower speaker commitment ratings than wenn, provide evidence for the CC scale. Experiment $4 \mathrm{~b}$ tested the interaction between two speaker commitment scales, namely, one of connectives (including weil 'because' and wenn/falls) and the other of adverbs (factive vs. non-factive, Liu, 2012). While factive and non-factive adverbs were rated equally natural for the factive causal connective, non-factive adverbs were preferred over factive ones by both CCs, with no difference between wenn and falls. This is discussed together with the result in Liu (2019), where the wenn/falls difference occurred in the absence of negative polarity items (NPIs), but disappeared in the presence of NPIs. This raises further questions on how different speaker commitment scales interact and why.

Keywords: conditional connectives, German, experiment, speaker commitment, non-at-issue meaning 


\section{INTRODUCTION}

Attitudinal expressions conveying speaker's beliefs or preferences are pervasive in natural language and communication. However, the related expressions can pose challenges to formal theories of grammar due to pragmatics (e.g., multidimensionality, context-dependence, and subjectivity) and gradience. Their formal modeling presupposes an empirically adequate characterization, for which experimental methods are useful, and sometimes, indispensable. This paper reports on a case study of German conditional connectives (CCs), as those in $(1)^{1}$. While conditionals are one of the most studied topics in cognitive science and linguistics, CCs have drawn attention to a much lesser extent than the other related lexical and grammatical devices. In the formal semantic literature, CCs as the English if are claimed to have no semantics in Kratzer's (1991) restrictor analysis of conditionals. The existing vast linguistic literature on the interpretation of conditionals (to just name a few, e.g., Iatridou, 1991; von Fintel, 1999, 2007, 2011; Arregui, 2005; Grosz, 2012; Elder and Jaszczolt, 2016) shows effects of various factors (tense, mood, and polarity items) on the interpretation of conditionals, as well as the effect of CCs (e.g., Dostie, 1987; Léard, 1987 on CCs in French, Montoliì, 2000; Schwenter, 2001 on CCs in Spanish, Ippolito and Su, 2014 on the Mandarin counterfactual CC yaobushi 'if-not', Hoeksema, 2012 on unless and among many others, also Declerck and Reed, 2001 on a comprehensive analysis of conditionals in English and Breindl et al., 2014 on connectives in German).

(1) Examples of German $\mathrm{CCs}^{2}$ :

wenn 'when, if', falls 'if, in case', insofern/sofern 'provided that,' vorausgesetzt dass/unter der Voraussetzung, dass 'provided that', angenommen dass 'assuming that,' im Falle, dass/für den Fall, dass/gesetzt (den Fall), dass 'in the event that,' unter der Bedingung, dass 'on condition that', unter der Annahme, dass 'assuming that', ausgenommen, dass 'except if'

As is known from the literature, conditionals are nonveridical (Giannakidou, 1998, 1999), that is, if-clauses do not entail the truth of the antecedent proposition. In addition, the literature also shows that the non-veridicality property of conditionals can be influenced by various factors. The first, and probably most studied, is tense and mood choice, which reflects subjective (non-veridical) judgments. Conditionals in languages with tense and mood morphology come in two sorts: indicative and subjunctive. While the former is non-veridical, the latter is antiveridical, i.e., it presupposes (or implicates) the falsity of the antecedent proposition. That is, in (2a) the speaker does not know if John gets a promotion or not,

\footnotetext{
${ }^{1}$ These expressions have different morphosyntactic properties (see Iatridou, 1991; Haegeman, 2003; Bhatt and Pancheva, 2006, a.o.). I put them under the unifying category of CC used in a semantic sense, due to the focus of the paper on the semantics and pragmatics of CCs and conditionals.

${ }^{2}$ The examples used throughout the paper do not reflect the author's personal opinions. Instead, they are only used to discuss grammar and linguistics.
}

but in (2b) the speaker presupposes that John did not get a promotion $^{3}$.

(2) (a) If John gets a promotion, he will do a big party.

(b) If John had got a promotion, he would have done a big party.

CCs, just as tense or mood choice, can reflect the speaker's doxastic assumptions at semantic and pragmatic levels. In this paper, I will use distributional and experimental evidence to argue that apparently similar CCs differ in lexical pragmatics (see Visconti, 1996 on CCs in Italian; Liu, 2019; Liu and Wang, 2021 on CCs in Mandarin) ${ }^{4}$. More specifically, they can express different degrees of credence toward the modified proposition. The meaning difference between various CCs in this regard can be formally modeled using speaker commitment ${ }^{5}$ scales $^{2}$ (Giannakidou and Mari, 2016) and as non-at-issue meanings (Simons et al., 2010) or, more precisely, an implicature resulting from the lexical choice between similar CCs. The paper focuses on the German CCs wenn vs. falls. It is organized as follows: Section "Non-at-Issue Meanings of wenn/falls in German" presents the distributional properties of wenn/falls, and provides an analysis relating falls to a weakened speaker commitment in contrast to wenn. Section "Experiments" reports on four experiments testing the analysis. Section "General Discussion and Conclusion" discusses the results and concludes the paper.

\section{NON-AT-ISSUE MEANINGS OF wenn/falls IN GERMAN}

In German, wenn is a more frequent word than falls ${ }^{6}$, but researchers do not have a consensus regarding the question whether wenn or falls is the prototypical CC. The handbook of Breindl et al. (2014) contains a comprehensive description of the German CCs in comparison to one another and also to other connectives. I will not go through the entire list, which also includes the discussion of wenn/falls-complement clauses, irrelevance conditionals (selbst/auch wenn/*falls 'even if') and except-conditionals (außer wenn/falls 'except if'). The authors

${ }^{3}$ It is worth noting that subjunctive conditionals do not always presuppose or implicate the falsity of the antecedent proposition, and thus, are not always counterfactual (see Anderson, 1951; Iatridou, 2000; Starr, 2019). On the other hand, Arregui and Biezma (2016) argue that the counterfactuality implicature cannot be canceled without good reason.

${ }^{4}$ The simple and complex CCs (used in purely descriptive terms) in natural language can differ in terms of among others, biconditionality, see Montoliìo (2000) on Spanish a condición de 'on condition that' and Liu and Barthel (2021) on German nur wenn 'only if'.

${ }^{5}$ Please note that the notion of commitment used in the paper is linked to the degree of the speaker's belief or credence in a proposition, as conveyed by the modifying expressions. This is different from the notion used in, for example, Krifka (2015) or Geurts (2019) for modeling human communication.

${ }^{6}$ The Wortschatz corpora (http://corpora.uni-leipzig.de, accessed October 27, 2020) of Leipzig University show that wenn has the frequency class 5, falls 10 . The frequency class of a word $\mathrm{FC}(\mathrm{w})$ is calculated based on the occurrence frequency of the word "Fw" in comparison to the frequency of the most frequent word "Fmax,"

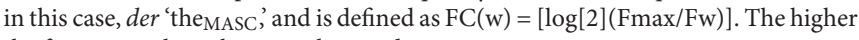
the frequency class, the rarer the word. 
also discuss the availability of causal and concessive readings for wenn but not for falls, which I will not deal with in this paper as the semantic or pragmatic status of the causal inference in indicative conditionals is debatable (see Volodina, 2006, 2011; Krzyżanowska et al., 2017; Krzyżanowska, 2019; SkovgaardOlsen et al., 2016), as well as that of the concessive reading. In a nutshell, syntactically speaking, wenn and falls, by and large, have similar distributions in terms of syntactic positions where they can occur, but there is a preference for wenn over falls in adverbial clauses in a sentence-final position (Breindl et al., 2014). Semantically, the most prominent difference between them lies in that wenn has both a conditional and a temporal reading ${ }^{7}$ whereas falls only has a conditional reading, which makes the use of the latter more restricted. Furthermore, Volodina (2006) relates their meaning differences to factivity and specificity: the non-factive specific use of wenn gives rise to ambiguity between a temporal (similar to sobald 'as soon as') and a conditional reading (similar to falls), see (3a); a non-factive generic use is possible for wenn but falls only allows a specific use, see (3b).

(3) (a) Wenn/Falls der Regen aufhört, gehen wir hin. when/if the rain stops, go we there 'If/When the rain stops, we will go there.' [conditional: wenn/falls, temporal: wenn/*falls]

(b) Wenn/Falls es wärmer wird, schmilzt das Eis. if it warmer gets melts the ice 'If it gets warmer, the ice melts/will melt.' [specific: wenn/falls, generic: wenn/*falls]

In the following of this section, I will present additional distributional properties of wenn and falls in different kinds of conditionals (von Fintel, 2007, 2011) and provide an analysis capturing their contrast.

\section{Distribution of wenn vs. falls}

Both wenn and falls are fine in indicative conditionals (3) and biscuit conditionals (which assert the consequent proposition with no conditional dependence on the antecedent), see (4).

Wenn/Falls du Hunger hast, gibt es Kekse
when/if you hunger have, gives it biscuits
auf dem Tisch.
on the table
'If you are hungry, there are biscuits on the table.'

But they differ, among others, in the following aspects. The first contrast (Contrast 1) is that wenn can, but falls cannot, be used in premise conditionals, such as in (5), which presupposes

\footnotetext{
${ }^{7}$ This does not mean that wenn is always ambiguous. For example, if we add a negative polarity item (NPI) such as jemals 'ever' into the antecedent, the resulting sentence (wenn der Regen jemals aufhört 'if the rain ever stops') only has a conditional reading. Furthermore, in this regard, the English when has also been argued to have both a temporal and a conditional reading, see Elder and Jaszczolt (2016) and their example (20) in it: When you follow that through you've got the means to give rise to a change in the method. Whether the ambiguity of the English when and the German wenn is comparable is an empirical question we will leave for future research.
}

that someone other than the speaker, in this case A, believes the truth of the antecedent proposition (Iatridou, 1991). The speaker accommodates the presupposition by using wenn, for which falls is odd $\mathrm{d}^{8}$. The same contrast holds for factive conditionals as in (6a), with the speaker or contextual presupposition that the antecedent is true, or (6b) from Breindl et al. (2014, p. 756). However, for the latter case, it seems more appropriate to translate the wennsentence using since; this point has been made in Volodina (2006, pp. 367, 368) who claims that a factive use of wenn does not allow a purely conditional reading or a temporal reading, but can receive a causal interpretation.

(5) A: Kai ist krank.

Kai is sick

'Kai is sick.'

B: Wenn/?Falls Kai krank ist, muss das Seminar ausfallen. if Kai sick is, must the seminar fail 'If Kai is sick, the seminar must be canceled.'

(6) (a) Wenn/?Falls ich es mir so recht überlege, könnte if I it me so right think, could das stimmen. it hold 'If I think about it seriously, this could be true.'

(b) (Max says to Moritz, who is present at the moment): Wenn/?Falls du nun mal wieder hier bist, lass uns if you now once again here are let us doch Schach spielen!

DOCH chess play

'Since you are now here again, let's do play the chess!'

The second - controversial - contrast (Contrast 2) is that falls is degraded in counterfactual conditionals (indicated by subjunctive mood in German, henceforth "subj" in the examples) or less preferred than wenn, see (7). For example, according to the "grammis", counterfactual use of falls is usually excluded, with some exceptions, as in their example (8) below. However, it is to note that there might be regional differences in this regard: Some native speakers I consulted with do not judge (7) with falls to be degraded.

$$
\begin{aligned}
& \text { Wenn/?Falls Kai krank gewesen wäre, hätte } \\
& \text { if Kai sick been be_subj has_subj } \\
& \text { das Seminar ausfallen müssen. } \\
& \text { the seminar fail must } \\
& \text { 'If Kai had been sick, the seminar would have } \\
& \text { been canceled.' }
\end{aligned}
$$

Solange die Boeing in Algier stand (...),
as long as the Boeing in Algiers was (...),

${ }^{8}$ It is to note that the speaker can use falls in order to not accommodate the antecedent proposition, for example, to indicate their doubt on A's assertion. In comparison, (5) is supposed to show that in the case that the speaker does accommodate the antecedent proposition, they need to use wenn but not falls.

${ }^{9}$ https://grammis.ids-mannheim.de/systematische-grammatik/2101 (accessed on 28.10.2020) 
wäre ein Kommandounternehmen denkbar

be_subj a commando conceivable

gewesen, falls die algerische Regierung die

been, if the Algerian government the

Zustimmung gegeben hätte. (Zeit, 21.6.1985, 2)

approval given has_subj

'As long as the Boeing was in Algiers (...), a commando

would have been conceivable if the Algerian government had given its approval.'

The third, uncontroversial contrast (Contrast 3) is that falls is out in counterfactual optatives, see (9). Following Grosz (2012), I assume that counterfactual optatives have no descriptive but presuppositional and expressive content, as illustrated below.

\section{Wenn ${ }^{*}$ Falls ich nur reich wäre! \\ if I only rich be_subj \\ 'If only I were rich!'}

(a) Presupposition: the speaker is not rich.

(b) Expressive: the speaker desires that s/he be rich.

The fourth contrast (Contrast 4) is that unlike wenn, falls is degraded with the quantifying adverb immer 'always' (Zaefferer, 1991). For the minimal pair in (10a), Zaefferer (1991, p. 216) argues "that explicitly quantified c-constructures are plural forms, bare $\mathrm{c}$-constructures with particles like if are transnumeral forms (unspecified with respect to number), and that bare c-constructures with falls are singular forms." Some speakers pointed out to me that the only, or the more prominent, reading of (10a) is temporal; this is in line with the claim made in Breindl et al. $(2014$, pp. 765,766$)$ that unlike wenn, falls cannot quantify over time points but is used only to hypothesize based on the truth or falsity of the antecedent proposition. However, as shown in (10b), the prominent reading of the sentence is clearly conditional, that is, the adverb quantifies over cases rather than times. In Section "Non-at-Issue Meanings of wenn/falls in German," I will argue instead that the contrast is due to the presupposition of always, which clashes with the meaning of falls.

(10) (a) Immer wenn/*falls Steffi gewinnt, wird gefeiert. always if Steffi wins, will celebrated 'Always, if Steffi wins, there will be celebrations.'

(b) Immer, wenn Sie dieses Symbol sehen, always if you this symbol see

können Sie den

can you the

Beitrag als PDF downloaden ${ }^{10}$. contribution as PDF download

'Whenever you see this symbol, you can download the contribution.'

Last but not least, while both wenn/falls license NPIs, such as auch nur irgendein 'even any' in (11), Liu (2012) claims that falls is degraded with factive evaluative adverbs, which show

\footnotetext{
${ }^{10}$ https://www.korrekturen.de/forum.pl/md/read/id/97832/sbj/kommabeiimmer-wenn/(accessed on 13.11.2020)
}

PPI (positive polarity item) behavior (Contrast 5), see her example in (12). The speakers I checked with have different intuitions about wenn in (12): It is fine for some, and for others, it is equally odd as falls.

\section{Wenn/Falls Du auch nur irgendeinen \\ if you also only any}

Artzt kennst, schreibe mir bitte.

doctor know, write me please

'If you know any doctor, please write to me.'

Wenn/?Falls die Vorschule leider keinen
if the preschool unfortunately no
Spielplatz hat, können die Kinder
playground has, can the kids
keinen Sport treiben.
no sports do
'If the preschool unfortunately has no playground,
the kids cannot do sports.'

Below, I will provide an analysis to account for the wenn/falls contrast based on the above observations.

\section{Analysis}

In the analysis, I will use two theoretical components: One is the speaker commitment scales used in Giannakidou and Mari (2016, 2021). Following their works, I assume "non-veridical equilibrium" (implying that $\mathrm{p}$ and $\neg \mathrm{p}$ as equal possibilities) to be the default for epistemic possibility, questions, and conditionals. That is, the speaker does not convey any preference for $\mathrm{p}$ or $\neg$ p. But the equilibrium of conditionals (as for questions) can be manipulated to produce bias (i.e., reduced or higher speaker commitment) through various lexical or grammatical devices (for German, see Reis and Wöllstein, 2010; Liu, 2019; Sode and Sugawara, 2019; Liu et al., 2021). In the following, I will provide several examples as triggers of speaker bias and then argue that the wenn/falls contrast can be captured along the lines. The other component is the notion of non-at-issue meanings (e.g., Simons et al., 2010; Tonhauser, 2012). I will argue using diagnostic tests from the theoretical literature that the speaker bias conveyed by falls in comparison to wenn is a non-at-issue meaning. While non-at-issue meanings can be semantic or conventional such as conventional presuppositions or conventional implicatures (Potts, 2005, a.o), I will show further that the non-at-issue of falls is of conversational nature as well as that the implicature is different from scalar implicatures.

Giannakidou (1998, 2014), in her (non)veridicality framework, has related attitudes (i.e., speaker's doxastic assumptions) to the notion of speaker commitment. In more recent works, Giannakidou and Mari (2016) argue that differences of attitudes can be modeled through speaker commitment scales (SCSs). For example, they apply the scale in (13) to capture the speaker's doxastic attitude toward the modified proposition. The necessity modal verb must conveys a stronger speaker commitment than the possibility modal adverb possibly, but a weakened speaker commitment in comparison to the unmodalized variant, which expresses full commitment. 
More committed $<$ unmodalized p, MUST p,

POSSIBLY $\mathrm{p}>$ Less committed
(a) It is raining.
(b) It must be raining.
(c) It is possibly raining.

It has to be further explored whether the SCSs can encode not only doxastic attitudes but also deontic or bouletic ones, and whether the perspectival agent must be the speaker or can be a sentence subject or another discourse referent. Furthermore, Giannakidou and Mari (2016) remain non-committed as to the semantic or pragmatic nature of this meaning difference, namely, whether it is at-issue or non-at-issue, and in the latter case, whether it is a conventional implicature or a conversational implicature. For example, while the weaker speaker commitment meaning of the possibility modal verb seems to be its semantics, it is unclear how the weakened speaker commitment meaning of must relates to its necessity modal meaning. It seems that alternatives and their commitment strength of SCSs are determined by a variety of factors ranging from the at-issue as well as non-at-issue content. Thus, these scales might be different from Horn scales based on entailment relations. With these open questions kept in mind, I will show that SCSs are very useful for modeling grammar of speaker commitment in general, and provide experimental work testing these in Section "Experiments."

First, for example, Zimmermann (2004) argues that the German discourse particle wohl (roughly 'probably') expresses a higher speaker credence in the truth of the proposition than the possibility adverb vielleicht 'possibly.' Thus, we can fit these alternations into a SCS in (14).

More committed <unmodalized p, WOHL p, VIELLEICHT $\mathrm{p}>$ Less committed

(a) Hein ist auf dem See.

'Hein is over the lake.'

(b) Hein ist wohl auf dem See.

'Hein is probably over the lake.'

(c) Hein ist vielleicht auf dem See.

'Hein is possibly over the lake.'

Second, Liu (2012) argues to distinguish between factive and non-factive evaluative adverbs in German, which show different distributions in entailment-canceling contexts (Simons et al., 2010). For example, leider and unglücklicherweise both mean roughly 'unfortunately', but the latter can occur in questions, conditionals and modals, whereas the former is odd in these contexts. Liu (2012) thus labels leider as a factive adverb and unglücklicherweise a non-factive one. This idea can be equally translated into a SCS as in (15).

(15) More committed <LEIDER p, UNGLÜCKLICHERWEISE $\mathrm{p}>$ Less committed

Third, Liu (2019) shows experimental evidence that in German and English conditionals, NPIs (jemals/überhaupt 'ever/at all') led to lower ratings of speaker commitment to the antecedent proposition in comparison to sentences without NPIs. This finding can be put into the SCS in (16). Whether this scale holds for all NPIs or not is a question beyond the scope of this paper.

(16) More committed $<$ NPI p, NPI p $>$ Less committed

Fourth, SCSs can also be used to model the difference between the clausal connectives. For example, in contrast to non-veridical CCs, causal connectives are veridical or factive operators, that is, they convey the speaker's full commitment to the truth of the antecedent (Giannakidou, 1998, et seq). This idea can also be put into a SCS, as shown in (17).

(17) More committed $<$ BECAUSE p, IF p $>$ Less committed

In the rest of this section, I will argue that SCSs are also useful for modeling the internal differences among the CCs.

That CCs can differ in degrees of speaker commitment is not new. For example, Visconti (1996, p. 555) claims that CCs can contribute secondary (in recent terms, 'nonat-issue') meanings concerning a 'propositional attitude' toward the modified propositions, such as the speaker's epistemic/doxastic/deontic/emotional evaluation toward the antecedent or the consequent. In Italian, Visconti claims that the CCs nel caso che 'in the case that,' nell'eventualità che 'in the eventuality that' and casomai 'if-ever' [made up of a simple CC caso 'in case, if' and a NPI mai 'ever'] differ in terms of the speaker's attitude toward the antecedent ' $p$ ' that is expressed at the level of conventional implicatures: While nel caso che is doxastically neutral, nell'eventualità che expresses a negative bias 'unlikely(p)' and casomai conveys an even stronger bias, namely, 'improbable(p).' Due to the different degrees of the bias, it is odd to use nell'eventualità che (or casomai) for modifying the antecedent that is simultaneously labeled as highly likely by the non-restrictive relative clause, whereas it is not a problem for nel caso che, as shown in her example (18) (Visconti, 1996, p. 559). The idea can be translated into a SCS in (19).

(18) Nel caso che/?Nell'eventualità che Giampiero riesca ad in case that/?in the event that Giampiero manages to affittare quella casa al mare

rent that house by the sea

- cosa che pare molto probabile - passeremo da lui una

- what that seem very likely- we will pass by him a settimana in luglio.

week in July

'In the case/?In the eventuality that Giampiero manages to rent that house by the sea -

which he almost certainly will - we'll go and stay with him for a week in July.'

(19) More committed <NEL CASO CHE p, NELL'EVENTUALITÀ CHE $p$, CASOMAI $p>$ Less committed

Visconti's proposal of treating the speaker assumption conveyed by these CCs as conventional implicature is a very insightful idea and is obviously useful for analyzing complex (i.e., multi-word) but compositional CCs (i.e., with transparent 
semantics which can be derived compositionally with the subparts of the CC) such as those in (20). The adjectives provide information about the speaker's doxastic (20a) or bouletic assumptions (20b) about the antecedent proposition. These meanings are logically and compositionally independent of the conditional core in these sentences, and thus are indeed conventional implicatures in the sense of Potts (2005). On the other hand, conventional implicatures are neither cancellable nor reinforceable, compared to conversational implicatures, which are cancellable and reinforceable. This raises the empirical question whether all the CCs express speaker bias at the dimension of conventional implicatures, or whether they can encode weaker, i.e., non-conventional, meaning.

(20) (a) In the impossible/possible/unlikely/likely event that...

(b) In the fortunate/unfortunate event that...

Liu and Wang (2021) provide distributional and experimental evidence that the Mandarin Chinese CC wanyi (lit, 'one of ten thousand, originally a numerical expression, used as a CC in modern Mandarin) conveys a weakened speaker commitment than ruguo 'if', as in (21)/(22). They treat this meaning difference at the dimension of non-at-issue-meanings (Simons et al., 2010).

$$
\begin{aligned}
& \text { Ruguo/Wanyi woxiawu you shijian, wo jiu he } \\
& \text { if I afternoon have time, I JIU with } \\
& \text { pengyou qu he kafei. } \\
& \text { friend go drink coffee } \\
& \text { 'If I have time in the afternoon, I will go have } \\
& \text { a coffee with my friends.' }
\end{aligned}
$$

The same scale can apply to the German CCs, such as in (23a): wenn/falls express speaker commitment of intermediate degree between im wahrscheinlichen Fall, dass 'in the probable event that' and im unwahrscheinlichen Fall, dass 'in the improbable event that.' Further, I argue that compared to wenn, falls expresses a weakened speaker commitment toward the antecedent proposition $(p)$, see (23b). That is, falls indicates that the speaker takes $p$ as not likely. This meaning acts at a separate layer of doxastic states, i.e., it does not target the question under discussion, and thus it is non-at-issue (Simons et al., 2010).

(23) (a) More committed $<$... im wahrscheinlichen Fall, dass', wenn/falls, 'im unwahrscheinlichen Fall, dass', ...> Less committed

(b) More committed $<$ WENN p, FALLS $\mathrm{p}>$ Less committed

Following this, falls has an attitudinal meaning at a separate layer of doxastic states, i.e., $\lambda$ p. $\neg$ likely $(p, x)$ with $\mathrm{x}$ as a free variable (for the attitudinal holder) whose value is to be determined by context (e.g., $x$ is the speaker, or the sentential subject). This is what I call 'weak unlikelihood implicature' (WUI). A sentence such as (24) expresses an at-issue content as proposed by Kratzer $(1986,1991)$ and paraphrased in $(24 a)$, and additionally, a non-at-issue content as in (24b).
Falls es regnet, werden die Strassen nass.

if it rains, become the streets wet

'If it rains, the streets will get wet.'

(a) At-issue content: the worlds (compatible with the speaker's knowledge) in which it rains are among the worlds in which the streets get wet.

(b) Non-at-issue content: $\neg$ likely(rain,x)

I will first address the non-at-issue and the implicature part of the proposal and then explain why it should be "weak."

Tonhauser (2012) puts forward three criteria along which atissue content differs from non-at-issue content: First, at-issue content can be directly assented or dissented with, but nonat-issue content cannot. Second, at-issue content addresses the question under discussion, but non-at-issue content does not. Third, at-issue content determines the relevant set of alternatives whereas non-at-issue content does not. I will apply one test Tonhauser proposes based on the first criterion in (25): As is shown, the conditional (i.e., at-issue) meaning in A's utterance can be assented or dissented with positive continuation (B1 and B2) but the speaker assumption about the antecedent proposition cannot (B3 and B4). This contrast speaks in favor of the non-atissue status or pragmatic nature of the bias encoded in falls.

(25) Diagnostic: Assent/dissent with positive continuation

A: Wenn/Falls es morgen regnet, kommt Paul if it tomorrow rains, comes Paul mit dem Auto. with the car

B1: Ja, richtig.Bei Regnen kommt er mit dem Auto. yes, right. with rain comes he with the car

B2: Nein, stimmt nicht. (Selbst) bei Regnen kommt no, holds not even with rain comes er nicht mit dem Auto. he not with the car

B3: \#Ja, richtig. Es regnet morgen wohl nicht. yes, right. it rains tomorrow probably not

B4: \#Nein, stimmt nicht. Es regnet morgen wohl. no, holds not. it rains tomorrow probably

['A: If it rains tomorrow, Paul will come by car. B1: Yes, right. If it rains, he will come by car. B2: No, not true. (Even) when it rains, he does not come by car. B3: \#Yes, right. It probably won't rain tomorrow. B4: \#No, not true. It probably will rain tomorrow.']

Furthermore, non-at-issue contents can project out of entailment canceling contexts (Simons et al., 2010; Liu, 2012). For example, in (26), the intuition is that the bias conveyed by falls survives embedding in the question operator, an entailment canceling context.

(26) Kommst du noch mit, falls es regnet? come you still with if it rains 'Are you still coming, if it rains?'

In addition, consider the minimal pair in (27) from Liu (2019): The relative clause in the sentence indicates the speaker's commitment to the antecedent proposition, which does not go along with the CC im unwahrscheinlichen Fall, dass but 
is ok with falls. This indicates that in the former case, the unlikelihood meaning component is semantic/conventional and thus uncancellable, whereas it is pragmatic/conversational and thus cancellable in the latter case.

(27) (a) \#Im unwahrscheinlichen Fall, dass es draußen regnet, in the improbable case, that it outside rains was ich glaube, bleibt Susanne zu Hause.

which I believe stays Susanne at home

'In the improbable case that it is raining outside, which I believe, Susanne will stay at home.'

(b) Falls es draußen regnet, was ich glaube, bleibt if it outside rains which I believe stays Susanne zu Hause.

Susanne at home

'If it is raining outside, which I believe, Susanne will stay at home.'

These data taken together indicate that the weak bias created by falls is a secondary, i.e., non-at-issue, content that is lexically triggered but contextually cancellable, and more precisely, an implicature (Grice, 1975; Potts, 2005; see Zakkou, 2018 for discussion of the reliability of the cancellability test). Here, a natural question arises whether it is a scalar implicature. However, if we compare the CC scale in (23b) with a typical Horn scale such as $<$ all, some $>$, there are at least the following three aspects where they differ: First, the scalar implicature, e.g., not all students came is computed based on the semantics of the sentence some students came, whereas it is not the case for wenn/falls $p, q$ as the negative bias does not target the conditional dependence between the antecedent and the consequent. Second, related to the first aspect, the bias by falls conveys speaker's assumptions that the hearer can ignore, as it does not target the QUD whereas scalar implicatures can target QUDs, e.g., How many students came? in the above example. The third and most straightforward argument against a scalar implicature analysis for the wenn/falls contrast is that the Horn scale is based on a proper entailment relation, e.g., all students came entails some students came, whereas this does not hold for wenn $p, q$ and falls $p, q$ : semantically, they both convey the same conditional relation between $p$ and $q$ in that all $p$-cases are $q$-cases. Thus, I take the implicature by falls to be different from scalar implicatures.

The naturally occurring examples in (28) show the speaker's awareness of the meaning difference between wenn and falls. Whereas wenn in (28a) can have either a conditional or a temporal reading, (29) is unambiguously meant as a conditional $^{11}$.

(28) (a) Wenn - und nicht falls - wir den nächsten großen

if - and not if - we the next big

Titel gewinnen-egal ob

title win - regardless whether

Europa-oder Weltmeisterschaft -, bauen wir hier

European or World Cup - build we here ein großes Zelt auf und lassen es

\footnotetext{
${ }^{11}$ Wenn and falls can also be used in coordination, such as wenn und falls, wenn oder falls indicating that they have common semantic properties and distinctive features at the same time (Breindl et al., 2014).
}

a big tent up and let it so richtig krachen! ${ }^{12}$

so right crash

'When - and not if - we win the next big title regardless of whether it is a European or a World Cup - we will put up a big tent here and let it rip!

(b) ...falls (ich schreibe bewußt falls und nicht wenn, ... if (I write deliberately if and not if da das nicht eindeutig aus Deinem because that not clearly from your ET[Entrag] hervorgeht) Du nur eine Frau entry shows you only a woman akzeptabel findest, die deutlich über deinem eigenen acceptable find, who well above your own Level liegt, bist DU das Problem, aber das level lie, are you the problem, but this weißt nur Du selbst. ${ }^{13}$

know only you yourself

'... if/falls (I deliberately write falls and not wenn, because that is not clear from your entry) you only find a woman acceptable who is well above your own level, you are the problem, but only you know that yourself.'

I argue that falls encodes a weak unlikelihood meaning (i.e., that the speaker does not take the antecedent proposition as likely) instead of a strong unlikelihood meaning (i.e., that the speaker takes a proposition as unlikely). The latter meaning is expressed by, for example, additive particles such as the English even. As shown in (29), a strong unlikelihood meaning will be too strong for falls.

(29) Ich rate dir dringend, tu dir selbst einen Gefallen und I advise you strongly do you yourself a favor and kombiniere Deutsch nicht mit Englisch. combine German not with English. Falls du es doch tust, wirst du es garantiert bereuen. ${ }^{14}$ if you it still do, will you it guaranteed regret 'I strongly advise you to do yourself a favor and not combine German with English. If you still do so, you're guaranteed to regret it.'

By this analysis, the degradation of falls in premise/factive conditionals (Contrast 1) results from the clash between the speaker presupposition and the WUI of falls. Falls is degraded in counterfactual optatives and arguably in counterfactual conditionals (Contrast 3 and 2) due to the counterfactual presupposition or implicature (i.e., speaker's anti-commitment to the antecedent proposition). This contradicts the meaning of falls, which presupposes the absence of bias to start with,

\footnotetext{
12 https://de.fifa.com/who-we-are/news/the-three-lions-new-den- 1816565 (accessed on 31.10.2020)

${ }^{13}$ https://community.elitepartner.de/forum/frage/wie-ist-diewahrscheinlichkeit-mit-mitte-30-eine-nette-frau-zu-finden-und-eine-familiezu-gruenden.79095/ (accessed on 13.11.2020).

${ }^{14}$ https://www.studis-online.de/Fragen-Brett/read.php?101,330531 (accessed on 01.11.2020).
} 
i.e., the non-veridicality of the antecedent proposition (dubbed as the "Non-veridicality Equilibrium," the default of epistemic possibility, in Giannakidou and Mari, 2021), and implicates the WUI. The reason why falls is acceptable in counterfactual conditionals for some speakers might be because the negative bias of falls is a conversational implicature (which is lexically triggered but needs contextual support) and thus cancellable or optional (Grice, 1989; Zakkou, 2018), or in general, there might be individual differences in the (quality of the) lexical representations of wenn/falls. The latter goes far beyond the scope of this paper and thus will not be addressed here. Another possibility is that subjunctive conditionals do not always presuppose or implicate the falsity of the antecedent proposition. But this is not a plausible explanation, as even though the counterfactuality inference does not always hold, it cannot be canceled without good reason (see Footnote 3 and the cited references therein).

For Contrast 4, I propose an alternative explanation to Zaefferer's (1991) account, namely, the wide-scope immer is presuppositional. It presupposes that the event in the antecedent takes place more than once, which clashes with the WUI by falls. For illustration, immer in (10) presupposes that Steffi wins more than once, but falls would convey that it is not likely that Steffi wins, thus their combination is odd. The degradation of falls in co-occurrence with factive adverbs (arguably compared to wenn, see Contrast 5) can also be attributed to the factivity presupposition of the adverb, in clash with its WUI. All in all, this shows that the proposed difference in terms of speaker commitment for wenn/falls is able to account for the listed distributional differences: falls, as the more restricted CC in comparison to wenn, has the proposed lexical pragmatics, which is cancellable and reinforceable through grammatical devices, as we will see in Section "Experiments." I leave it open for now whether some of the differences can be captured differently, but will discuss several alternative accounts, which I argue are in line with the proposed one.

The present analysis for wenn/falls echoes the observation occasionally made in the previous literature, for example, by Breindl et al. (2014, pp. 114, 115): "The difference between wenn and falls has to do with the probabilities of the occurrence of the antecedent" (translated from German). They use the example in (30) to argue that the speaker, being aware of their differences, uses one CC or the other to indicate implicitly their assessment of the probability of the antecedent proposition (i.e., speaker commitment).

(30) Rushdie: um es grob zu sagen: falls Gott existiert, Rushdie: for it roughly to say if God exists, wird er sich um die "Satanischen Verse" will he himself about the Satanic Verses nicht scheren; wenn er nicht existiert, not care; if he not exists, auch nicht. (Der Spiegel, 11.05.1992, S. 214)

also not

'Rushdie: To put it roughly, if God exists, he won't care about the "Satanic Verses"; if he does not exist, he won't, either.'
So far, we have seen distributional properties of the wenn/falls contrast and I proposed that the two CCs differ in degrees of conveyed speaker commitment. In the following, I will report on experimental work that tested the proposed contrast.

\section{EXPERIMENTS}

I conducted three experiments to test the proposed analysis above, as well as a fourth experiment on the interaction between two different SCSs. In addition, I will also report on the related German experiment from Liu (2019).

\section{Experiment 1}

The original assumption for Experiment 1 was that if falls carries a negative bias in comparison to wenn, as illustrated in (31), then it might tend to occur more naturally with events (or, propositions) that are less likely, i.e., more naturally with $\mathrm{p} 3$ than with p1 in (32). This assumption turned out to be problematic. I report on this experiment here nevertheless, as it is important to showcase potential pitfalls and necessary "precautions" to take for testing lexical pragmatics in general.

(31) More committed $<$ WENN p, FALLS p $>$ Less committed

(32) More likely $<$ p1, p2, p3 $>$ Less likely

\section{Materials and Methods}

Experiment 1 was a rating study based on a $2 \times 3$ within-subjects design, with one factor being CC (wenn/falls) and the other factor being the likelihood of the event in the conditional antecedent $p$ (in three levels, i.e., very likely/likely/unlikely), see Table $\mathbf{1}$. The starting prediction was that due to the weakened speaker commitment by falls in contrast to wenn, it might be degraded in combination with very likely and likely events in comparison to the other conditions.

Twenty-four items were used, with one example in (33), as well as 84 additional filler items. The critical stimuli are provided in the Supplementary Materials (Test sentences of Experiment 1$)^{15}$.

(33) (a) Wenn die Läden am Montag geöffnet sind, gehen if the shops on the Monday opened are, go Tom und Lisa einkaufen.

Tom and Lisa shop

(b) \#\#Falls die Läden am Montag geöffnet sind, gehen if the shops on the Monday opened are, go

${ }^{15}$ As the fillers involved test materials of other experiments, they are not provided in the Supplementary Materials.

TABLE 1 | Factors, conditions and predictions of Experiment 1.

\begin{tabular}{lcc}
\hline Events & wenn & falls \\
\hline Very likely & $1:(\mathrm{a})$ & $2: \# \#(\mathrm{~b})$ \\
Likely & 3: (c) & $4: \#(\mathrm{~d})$ \\
Unlikely & $5:(\mathrm{e})$ & $6:(f)$
\end{tabular}


Tom und Lisa einkaufen.

Tom and Lisa shop

(c) Wenn die Läden am Samstag geöffnet sind, gehen if the shops on the Saturday opened are, go Tom und Lisa einkaufen. Tom and Lisa shop

(d) \#Falls die Läden am Samstag geöffnet sind, gehen if the shops on the Saturday opened are, go Tom und Lisa einkaufen. Tom and Lisa shop

(e) Wenn die Läden am Sonntag geöffnet sind, gehen if the shops on the Sunday opened are, go Tom und Lisa einkaufen.

Tom and Lisa shop

(f) Falls die Läden am Sonntag geöffnet sind, gehen if the shops on the Sunday opened are, go

Tom und Lisa einkaufen.

Tom and Lisa shop

('If the shops are open on Monday/Saturday/Sunday, Tom and Lisa will go shopping.')

As the German CC wenn has both a temporal (i.e., when) and a conditional (i.e., if) reading in present indicative, a temporal adverb was used in the antecedent so that the conditional reading of wenn becomes more plausible than the temporal reading. The focus was on whether the naturalness of falls decreases by the likelihood increase of $p$. The events were chosen and ordered based on common knowledge in the German context. They were tested informally with 10 subjects (undergraduate students of Osnabrück University). The subjects saw a list of three-event pairs (e.g., the shops are open on Monday/Saturday/Sunday) in different orders and were asked to order the events in each pair by their likelihood. The results show that the scales were all valid ${ }^{16}$.

The experiment was conducted online using the SoSci Survey $^{17}$. 36 undergraduate students (25 female, 11 male; 35 between 18 and 29 years old, 1 under 18$)^{18}$ of Osnabrück University took part in the study online for course credits. The participants each saw 108 sentences in total, which were presented one by one in the middle of the computer screen, and they rated the naturalness of each sentence (0: unnatural, 1 : natural). Our predictions were that $(33 \mathrm{~b} / \mathrm{d})$ would receive lower ratings than $(33 \mathrm{a} / \mathrm{c} / \mathrm{e} / \mathrm{f})$, as the negative bias by falls might clash with the likely events of the shops being open on Monday or Saturday in the German context.

\footnotetext{
${ }^{16}$ Please note that the studies reported in the paper were all conducted long before the Covid-19 Pandemic, as today (May 04, 2021 in Germany), it is not unusual that the shops are closed on Monday or Saturday.

${ }^{17}$ https://www.soscisurvey.de/

${ }^{18}$ All the studies reported were conducted between 2016 and 2017, and we only collected binary gender information. We collected age information using ranges for Experiments 1, 3, and 4b. While we also collected dialectal information (i.e., whether the subjects speak any German dialect and if yes, which ones) in the experiments, there was way too little data to report here. We did not control whether subjects were bilingual or not.
}

\section{Results}

All analyses were performed using mixed effects linear regression models. The models were constructed using the lme4 package (Baayen et al., 2008; Bates et al., 2012) in R (R Core Team, 2018). The reported model is the maximal model that converged (Barr et al., 2013). The model included CC and Event-likelihood (with interaction term) as fixed effects. Furthermore, it included random intercepts for subjects, items and stimuli order, as well as random by-subject and by-item slopes for the effects of CC and Event-likelihood.

The results (see Table 2 and Figure 1) showed neither the interaction nor the main effect for CC. That is, the comparison between wenn and falls was not significant $(t=0.15, p=0.88)$. For the Event-likelihood, there is a numerical difference in the naturalness rating for likely events when compared to either unlikely or very likely events. However, these contrasts, too, fail to reach significance [Tukey's test for multiple comparisons of means: $t=1.52, p=0.26$ (very likely vs. likely); $t=1.63, p=0.215$ (unlikely vs. likely)].

\section{Discussion}

Experiment 1 did not confirm the prediction and thus does not provide evidence for the proposed account of the wenn/falls contrast. This can mean that the two connectives are interchangeable in the conditional use. Alternatively, the methods used here might be problematic. First, some of the fillers involve unlicensed polarity items, e.g., jemals 'ever' in positive sentences, which are ungrammatical (see Ladusaw, 1980; Giannakidou, 2011; Liu et al., 2019). This might have contributed to the ceiling effect for the wenn/falls sentences. Second, the attitude by falls is a speaker-oriented (i.e., subjective) meaning

TABLE 2 | Descriptive statistics of Experiment 1.

\begin{tabular}{lllll}
\hline Condition & CC & Event & Rating & SE \\
\hline 1 & wenn & Very likely & 0.95 & 0.02 \\
2 & falls & Very likely & 0.97 & 0.02 \\
3 & wenn & Likely & 0.88 & 0.03 \\
4 & falls & Likely & 0.88 & 0.03 \\
5 & wenn & Unlikely & 0.97 & 0.01 \\
6 & falls & Unlikely & 0.96 & 0.02
\end{tabular}

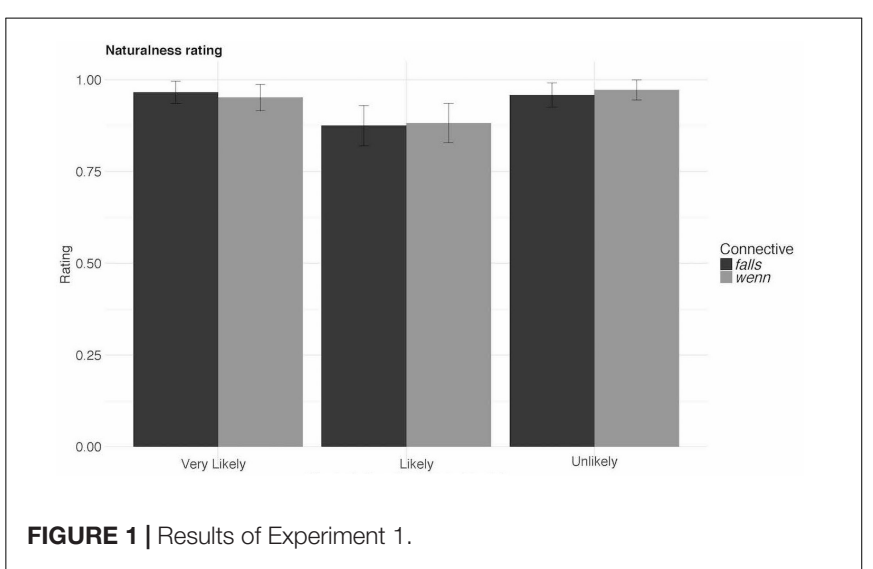


at a separate dimension (i.e., non-at-issue), i.e., it can be ignored from the hearer's (i.e., subjects') perspective. In other words, the contrast is context-dependent, i.e., present in some contexts and absent in others (as Experiments 2-4 will show). Thirdly, the naturalness rating studies with the binary scale was maybe not sensitive enough to measure such subtle lexical pragmatics (e.g., due to shallow processing).

\section{Experiment 2}

Experiment 2 used the forced lexical choice paradigm. It was based on the assumption that if the wenn/falls contrast was real, then, given both as possible lexical items to use, speakers would opt for one or the other in a conditional expression depending on the context, i.e., their degree of commitment or credence in the antecedent. More specifically, in a context where the protagonist is positively biased toward the antecedent proposition, they would use wenn more often than falls; in a context where the protagonist is negatively biased toward the antecedent proposition, a reverse pattern is to be expected, see Table 3.

\section{Materials and Methods}

Experiment 2 was based on a one factorial within-subjects design with two levels for the factor CONTEXT, encoded in the sentence preceding the conditional sentence. Bearing in mind that the negative bias of falls is subjective meaning, I used a thirdperson protagonist to keep the doxastic anchoring constant, i.e., to prevent subjects from taking egocentric perspectives. The protagonist either believes $p$ or not.

The subjects were asked to choose among wenn, falls and a mismatching control item such as oder 'or.'

(34) Susannehatsich morgen füreinen Tagfrei genommen. Susanne has herself tomorrow for a day free taken Sie \{glaubt/glaubt nicht\} dass es morgen regnet und denkt: She believes/believes not that it tomorrow rains and thinks: es morgen regnet, bleibe ich zu Hause. it tomorrow rains, stay I at home 'Susanne has taken tomorrow for a day off. She \{believes/doesn't believe\} that it will rain tomorrow and is thinking: it rains tomorrow, I will stay at home'
(a) wenn
(b) falls
(c) oder

Twenty-four items such as (34) were used, as well as 48 fillers. The critical stimuli are provided in the Supplementary Materials (Test sentences of Experiment 2). The experiment was programmed in Python and conducted in the behavorial lab of the Institute of Cognitive Science of Osnabrück University. 52 undergraduates ( 29 female, 23 male; mean age $=21.2, S D=1.7$ ) of Osnabrück University participated in the study for course credits.

TABLE 3 | Factor, conditions, and predictions of Experiment 2.

\begin{tabular}{ll}
\hline Context & wenn vs. falls \\
\hline Belief-context & wenn preferred to falls \\
Disbelief-context & falls preferred to wenn
\end{tabular}

\section{Results}

Wrong answers, i.e., answers with the mismatching lexical items [e.g., oder 'or' in (34)], were excluded from the data analysis. The response (see Table 4) in this experiment is binary, not numeric (i.e., a binary choice between falls and wenn), therefore all analyses were performed with mixed logistic regression models. The model included the answer choice (falls/wenn) as dependent variable and the CONTEXT (belief/disbelief) as predictor variable. The random effects structure included random intercepts for subjects, items and stimuli order, as well as random by-subject slopes for the fixed effect. The model reported is the maximal model that converged. The model has a good fit (precision $=0.79$, recall $=0.78$ ) and performs significantly better than a baseline of guessing a response $(p<0.0001)$. It yields a significant effect of CONTEXT ( $t=6.19, p<0.0001)$, that is, subjects are significantly more likely to choose falls under the disbelief-condition and wenn in the belief-condition.

\section{Discussion}

Experiment 2 shows that the doxastic agent chose falls over wenn if they have a low degree of credence toward the modified antecedent proposition. As the materials use both CCs in the sentence-initial position, I take the results to reflect meaning differences instead of syntactic preferences (in a sentence-final position, as Breindl et al., 2014 point out). That is, they provide positive evidence for the wenn/falls contrast in terms of degree of speaker commitment.

\section{Experiment 3}

Experiment 1 did not confirm the wenn/falls contrast. As mentioned above, this can be due to the context-dependence of the contrast due to, among others, the subjective (speakeroriented) nature of the bias encoded in falls. For this reason, Experiment 3 included an additional relative clause commenting on the conditional antecedent. The rationale was that in this way, the attitudes encoded in the CC and the relative clause had the same anchoring toward the speaker. While this was also controlled in Experiment 2, Experiment 3 was conducted to find out whether the bias is cancellable (by a RC conveying speaker's disbelief in the antecedent proposition) or reinforceable (by a $\mathrm{RC}$ conveying speaker's belief in the antecedent proposition). The results can shed further light on the nature of the bias. If the meaning difference is cancellable and reinforceable, we can conclude that it is a pragmatic difference.

\section{Materials and Methods}

Experiment 3 was a rating study based on a $2 \times 2$ factorial within-subjects design, with the factor CC (wenn/falls) and RC (relative clause) expressing a likelihood/unlikelihood propositional attitude toward $p$. The method and procedure were

TABLE 4 | Results of Experiment 2.

\begin{tabular}{llc}
\hline Context & wenn & falls \\
\hline Belief-context & 442 & 185 \\
Disbelief-context & 177 & 436
\end{tabular}


similar as in Experiment 1. 24 items were used as well as 72 fillers. Half of the items used RCs as in (35) and the other half used RCs as in (36). The critical stimuli are provided in the Supplementary Materials (Test sentences of Experiment 3). We did not control the likelihood of the antecedent and used the unlikely conditions due to lack of contrast for this manipulation in Experiment 1.40 undergraduates (25 female, 15 male; 39 between 18 and 29 years old, 1 between 30 and 39) of Osnabrück University participated in the experiment for course credits.

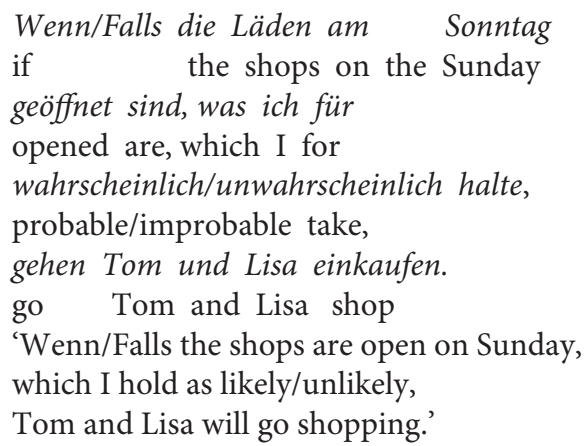

\author{
Wenn/Falls die Läden am Sonntag geöffnet sind, \\ if the shops on the Sunday opened are, \\ was ich glaube/nicht glaube, \\ which I believe/not believe \\ gehen Tom und Lisa einkaufen. \\ go Tom and Lisa shop \\ 'Wenn/Falls the shops are open on Sunday, \\ which I believe/do not believe, \\ Tom and Lisa will go shopping.'
}

\section{Results}

All analyses of the data (see Table 5 for descriptive statistics) were performed using mixed effects linear regression models. The models were constructed using the lme4 package in $\mathrm{R}$ (Baayen et al., 2008; Bates et al., 2012; R Core Team, 2018). All contrasts of interest, i.e., CC and RC, were sum coded and included as fixed effects in the models. The reported models are the maximal models that converged.

The first model included CC and RC (with interaction term) as fixed effects. Furthermore, it included random bysubject and by-item intercepts, as well as random by-subject and by-item slopes for the effects of CC and RC (and their interaction). Neither of the two main effects was significant. There was a significant interaction between CC and RC $(t=2.15, p=0.03)$ : in the belief-condition, wenn was rated more natural than falls. The reverse pattern was found in the disbelief-condition. Pairwise comparisons between all four conditions, however, showed no significant differences between either of them, indicating that the interaction effect is highly nuanced.

Furthermore, the RCs in the experiment included 12 items with was ich für wahrscheinlich/unwahrscheinlich halte ("which I deem likely/unlikely'), and another 12 with was ich glaube/nicht glaube ('which I believe/do not believe'). Thus, I did an
TABLE 5 | Descriptive statistics of Experiment 3.

\begin{tabular}{lllll}
\hline Condition & CC & RC & Rating & SE \\
\hline 1 & wenn & Belief & 0.78 & 0.05 \\
2 & wenn & Disbelief & 0.73 & 0.06 \\
3 & falls & Belief & 0.73 & 0.06 \\
4 & falls & Disbelief & 0.79 & 0.05 \\
\hline
\end{tabular}

(A) Descriptive statistics of Experiment 3 with the $\mathrm{RC}$ was ich glaube/nicht glaube 'which I believe/do not believe'.

\begin{tabular}{lllll}
\hline 1 & wenn & Belief & 0.66 & 0.04 \\
2 & wenn & Disbelief & 0.66 & 0.04 \\
3 & falls & Belief & 0.77 & 0.04 \\
4 & falls & Disbelief & 0.82 & 0.04 \\
\hline
\end{tabular}

(B) Descriptive statistics of Experiment 3 with the $\mathrm{RC}$ was ich für wahrscheinlich Iunwahrscheinlich halte 'which I deem likely/unlikely'.

\begin{tabular}{lllll}
\hline 1 & wenn & Belief & 0.91 & 0.03 \\
2 & wenn & Disbelief & 0.81 & 0.04 \\
3 & falls & Belief & 0.70 & 0.04 \\
4 & falls & Disbelief & 0.76 & 0.04 \\
\hline
\end{tabular}

additional test to see whether and to what extent there were differences between the two types of predicates. First, a model was constructed which included the type of the predicates (henceforth, PREDICATE) as a third fixed effect and included a three-way interaction term between PREDICATE, CC, and RC. The random effects structure was identical to that of the first model. The new model indicates a significant effect for PREDICATE $(t=2.60, p=0.009)$, but no other main effects or higher-order interactions between PREDICATE and $\mathrm{CC}$ or RC. However, the reader should keep in mind that the factor PREDICATE was not a systematically controlled condition within items. Thus, we cannot exclude the possibility that any effect was due to confounding influences that rendered some items more natural than others. Nevertheless, it may serve as the first indication of an effect, which can be further explored in future studies.

To further explore the effect of the RC, separate models were created for the two sets of items, see Figure 2 and Tables 5A,B. Both models thus used half of the data set and included CC and RC (with interaction term) as fixed effects. Again, the random effects structure included random by-subject and by-item intercepts, as well as random by-subject slopes for the effects of CC and RC.

Firstly, for the items that used an RC with the verb glauben/nicht glauben 'believe/not believe', no significant effects were found (see Table 5A). Neither the main effects nor the interaction turned out to be significant, that is, there was no systematic effect of either factor. For the items that used the RC containing wahrscheinlich/unwahrscheinlich 'likely/unlikely', there was a significant interaction between CC and RC $(t=2.05$, $p=0.04)$, see Table 5B. However, neither of the main effects turned out to be significant and paired-tests also showed no 


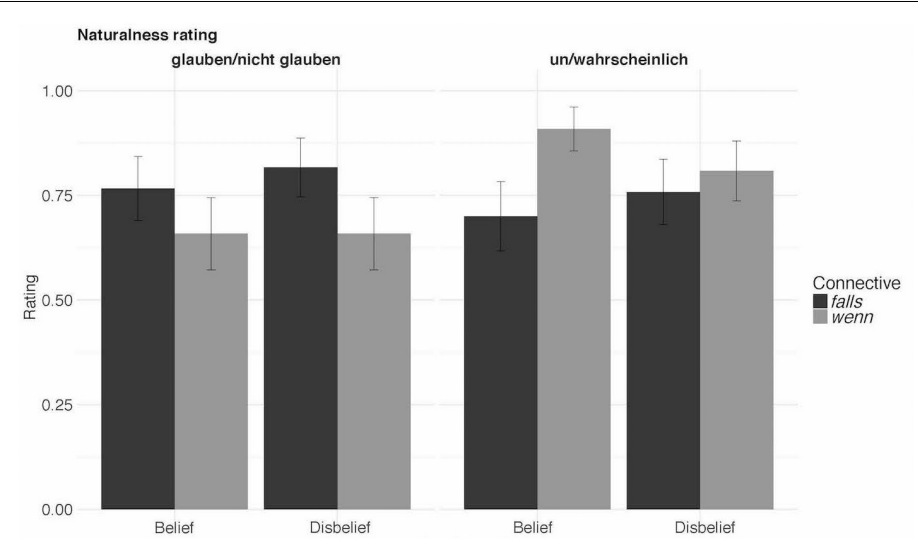

FIGURE 2 | Results of Experiment 3.

significant contrast between any of the comparisons, which indicates a high degree of variation in the data.

\section{Discussion}

The naturalness rating results of Experiment 3 are compatible with the lexical choice results of Experiment 2: Wenn is preferred over falls in the belief-context and vice versa in the disbeliefcontext. On the other hand, the results in Experiment 3 are also not straightforward to interpret.

As the analysis including PREDICATE shows, the overall interaction effect was mainly driven by the interaction among the items using the RC was ich für wahrscheinlich/unwahrscheinlich halte ('which I deem likely/unlikely'). The wenn-sentences were rated more natural with these than with was ich (nicht) glaube ('which I believe/do not believe'). A possible explanation for the effect of PREDICATE lies in their difference in terms of speaker commitment. As (37) shows, was ich glaube/nicht glaube ('which I believe/do not believe') conveys the speaker's full commitment or anti-commitment, whereas was ich für wahrscheinlich/unwahrscheinlich halte ('which I deem likely/unlikely') conveys the speaker's weakened commitment or weakened anti-commitment.

\section{(37) More commitment $<$ GLAUBEN, WAHRSCHEINLICH, UNWAHRSCHEINLICH, NICHT GLAUBEN>} Less committed

A full account of these differences presupposes a good understanding of the predicates believe and probable used in the RC, which goes beyond the scope of this paper. For example, it was pointed out to me (Juliane Schwab, p.c.) that the addition of certain adverbs improves the believe-sentences, as in (38). The effect of adding durchaus 'quite' weakens the speaker commitment, bearing a similar effect as wahrscheinlich 'likely'. The addition of eigentlich 'actually' signals that there is a contextual expectation (e.g., of the shops being open) set by the antecedent which the speaker rejects with the use of the RC (see Bergena and Boskerb, 2018).

$$
\begin{aligned}
& \text { Wenn die Läden am Sonntag geöfnet sind, } \\
& \text { if the shops on the Sunday opened are, }
\end{aligned}
$$

\begin{abstract}
was ich durchaus glaube/eigentlich nicht which I quite believe/actually not glaube, gehen Tom und Lisa einkaufen. believe go Tom and Lisa shop 'If the shops are open on Sunday, which I quite believe/actually do not believe, Tom and Lisa will go shopping.'
\end{abstract}

As to falls, it has been noted that the negative bias generated by it is not always cancellable, as can be seen in (39) from Liu (2019), attributed to an reviewer.

$$
\begin{aligned}
& \text { ??Falls es draußen regnet-und ich bin } \\
& \text { if it outside rains - and I am } \\
& \text { mir fast sicher, dass es das tut } \\
& \text { me almost certain, that it this does } \\
& \text { - bleibt Susanne zu Hause. } \\
& \text { - stays Susanne at home } \\
& \text { 'If it is raining outside - and I am almost certain } \\
& \text { that it is - Susanne will stay at home.' }
\end{aligned}
$$

However, the native speakers I checked with have no problems with this sentence. Moreover, the data in Table 5A show no difference between the CC or the polarity of the RC. This means that the bias of falls is reinforceable (by the negative RC) and cancellable (by the positive RC). With the questions about the predicates (believe, certain, likely) left for the future, overall, Experiment 3 shows that the speaker bias encoded in falls is a conversational, non-at-issue meaning as is proposed in Section "Non-at-Issue Meanings of wenn/falls in German." This is also in line with the results of Experiment 1.

\section{Experiment 4}

Experiments 1-3 tested the wenn/falls contrast directly with different measures. The results were mixed with no evidence in Experiment 1, with evidence in Experiment 2 and with inconclusive results (weak evidence in the predicted direction) in Experiment 3. In this section, I report two additional experiments addressing the question of how the SCS of CCs interacts with 
other SCSs. Experiment 4a on the interaction of the CC scale and the NPI scale (16) refers to the German study reported in Liu (2019), which I summarize here. In comparison, Experiment $4 \mathrm{~b}$ tested the interaction of the CC scale and the EDAV scale, as shown in (15). The NPI and the EADV scales differ from each other in that the former conveys weakened speaker commitment and the latter high speaker commitment, in line with their distributional requirements (NPIs for negative contexts and EADV for positive contexts). The purpose of these two studies is to reveal the CC contrast by checking their interaction with different SCSs.

\section{Experiment 4a: Summary of Liu (2019)}

In Liu (2019), the author reports on a "speaker commitment" rating experiment in German addressing the difference between wenn/falls, the effect of NPIs jemals/überhaupt 'ever/at all,' and their interaction. Subjects were given scenarios, e.g., (40), consisting of 4 sentences ( $\mathrm{S} 1-\mathrm{S} 4$ ) presented one by one: $\mathrm{S} 1$ sets the context; S2 contains a conditional sentence in one of the four combinations, with half of them containing jemals and the other half überhaupt (e.g., wenn-überhaupt, wenn+überhaupt, falls-überhaupt, falls+überhaupt); S3 asks the subjects to rate the degree of the protagonist's commitment to the antecedent on a 5 -point Likert scale ( $1=$ certainly not, $5=$ certainly yes). S4 is a comprehension question. The results show a significant effect of CC (in that the falls conditions received lower ratings than the wenn conditionals), a significant effect of NPI (with high ratings in the conditions without NPIs than with NPIs) and a significant interaction. Both scales in (41) and (42) are confirmed, with a significant CC contrast in the absence of NPIs, which disappears in the presence of NPIs.

(40) S1: Melanie sucht nach einem Sommerkleid. 'Melanie is looking for a summer dress.'

S2: Sie denkt: "Wenn/Falls ich (überhaupt) ein schönes finde, kaufe ich es sofort."

'She thinks,' "If I find a nice one (at all), I will buy it immediately."

S3: Glaubt Melanie, dass sie ein schönes Kleid findet?

'Does Melanie believe that she will find a nice dress?'

S4: Möchte Melanie warme Stiefel kaufen?

'Does Melanie want to buy warm boots?'

(41) NPI SCS: More committed $<$ NPI $p$, NPI p $>$ Less committed

(42) CC SCS: More committed $<$ WENN p, FALLS p $>$ Less committed

If Experiment 2 provides indirect evidence for the CC scale, the finding of this study complements it with direct evidence in favor of the wenn/falls contrast. But while Liu (2019) focuses on CCs and NPIs from a cross-linguistic perspective by comparing German vs. English, the current paper provides a more detailed descriptions and a set of experiments on wenn/falls with both theoretical and methodological implications.

\section{Experiment 4b}

Experiment $4 \mathrm{~b}$ also tested the interaction between the CC SCS with another SCS, namely, by evaluative adverbs (EADV). Liu (2012) presents distributional facts of apparently similar EADVs in German and argues that they differ in terms of factivity. Factive EADVs occur only in veridical contexts, whereas nonfactive EADVs are more tolerant, e.g., they can also occur in non-veridical contexts. Without going into detail, their distinction can be illustrated with (43). Both EADVs mean unfortunately, but in, for example, questions and conditionals (as non-veridical or entailment-canceling contexts), leider is degraded in comparison to unglücklicherweise, which Liu attributes to their difference in degrees of factivity, i.e., speaker commitment.

\section{(43) EADV SCS: More committed $<$ LEIDER p, UNGLÜCKLICHERWEISE $\mathrm{p}>_{\text {Less }}$ committed}

Experiment 4b, addressing the CC SCS and the EADV SCS, was based on the assumption that the degree of speaker commitment by one expression should be coherent with that of its co-occurring expression. Thus, both CCs should favor nonfactive EADVs more than factive ones and factive EADVs should favor wenn over falls with no difference between the CCs in the case of non-factive EADVs.

\section{Materials and Methods}

Experiment $4 \mathrm{~b}$ used a $3 \times 2$ factorial within-subjects design, with the factor CONNECTIVE (factive vs. non-factive, i.e., weil 'because' vs. wenn/falls) and EADV with the levels factive (e.g., leider) and non-factive (e.g., unglücklicherweise). 36 items such as (44) as well as 72 fillers were used. The critical stimuli are provided in the Supplementary Materials (Test sentences of Experiment $4 \mathrm{~b}$ ). The procedure was similar as in Experiment 1, except that the subjects gave naturalness ratings on a 5 -point Likert scale ( $1=$ unnatural, $5=$ natural $)$. 42 undergraduates (28 females, 14 males; 40 between 18 and 29 years old with 1 under 18 and 1 between 30 and 39) of Osnabrück University participated in the experiment for course credits.

(44) S1: Katja stellt einen BAföG-Antrag. Katja makes a BaföG-application 'Katja applies for BAföG.'

S2: Weil/Wenn/Falls sie den Abgabetermin because/if/if she the deadline leider/unglücklicherweise verpasst, bittet sie unfortunately misses, asks she um eine Fristverlängerung. for one deadline extension 'Because/If/In case she unfortunately misses the deadline, she will ask for an extension of the deadline.'

\section{Results}

All analyses were performed using mixed effects linear regression models. The model was constructed using the 
lme4 package in $\mathrm{R}$ (Baayen et al., 2008; Bates et al., 2012; R Core Team, 2018). The reported model is the maximal model that converged. The model included CONNECTIVE and EADV (with interaction term) as fixed effects. Furthermore, it included random intercepts for subjects and items, as well as random by-subject and by-item slopes for the effects of CC and EADV.

The results show a highly significant CONNECTIVE $\times$ EADV interaction (LRT $=56.92, p<0.0001$ ), see Table 6 and Figure 3 . First, weil-sentences received significantly higher naturalness ratings overall than either wenn- or falls-sentences (weil vs. wenn: $t=8.19, p<0.0001$; weil vs. falls: $t=9.59, p<0.0001)$, even though an reviewer pointed out rightly that the weil-sentences would have been more natural in present perfect (i.e., verpasst hat 'has missed'). Second, for the causal connective weil 'because' both factive and non-factive EADVs were rated as equally natural. Third, non-factive EADVs were preferred over factive ones in the case of both CCs (wenn: $t=4.66, p=0.0001$, falls: $t=7.30$, $p<0.0001$ ), whereas wenn and falls did not differ significantly from each other in their ratings.

\section{Discussion}

Experiment $4 \mathrm{~b}$ shows that both CCs are degraded with either type (i.e., factive/non-factive) of EADVs in comparison to the factive causal connective. Concerning CCs, it shows that sentences with either CC are degraded in co-occurrence with factive EADVs in comparison to those with non-factive EADVs. That is, the

TABLE 6 | Descriptive statistics of Experiment 4b.

\begin{tabular}{lllll}
\hline Condition & Connective & EADV & Rating & SE \\
\hline 1 & falls & Factive & 2.04 & 0.07 \\
2 & falls & Non-factive & 2.89 & 0.08 \\
3 & weil & Factive & 3.61 & 0.08 \\
4 & weil & Non-factive & 3.60 & 0.08 \\
5 & wenn & Factive & 2.19 & 0.07 \\
6 & wenn & Non-factive & 2.73 & 0.09
\end{tabular}

prediction that factive EADVs should favor wenn over falls was not borne out. This makes Contrast 5 as in the example of (12) invalid. We can thus conclude that in general, factive EADV disprefer non-veridical contexts as created by both CCs, compared to non-factive EADVs, which are non-veridical as CCs.

These results have at least the following implications: First, in Karttunen's (1971) term, EADVs are 'semi-factive', i.e., they lose their factivity in certain contexts including questions, conditionals, and modals (see also Asher, 2000). But earlier work does not make a distinction among EADVs. Experiment $4 \mathrm{~b}$ shows that EADVs indeed differ in terms of factivity, as argued in Liu (2012). Second, there exists a general constraint on co-occurring expressions with attitudinal meanings, namely, they need to agree with (or at least not clash with) each other. While this constraint needs further qualification and empirical validation, it is probably related to the notions of (in)coherence or (dis)harmony (Lyons, 1977). The factive causal connective is harmonious with both types of EADVs, as EADVs, despite their difference, express high degrees of commitment (i.e., toward full-commitment). Factive EADVs are less harmonious with CCs because the latter are non-factive, which are thus more coherent to combine with non-factive EADVs.

Furthermore, all ratings for sentences in Experiment $4 \mathrm{~b}$ are very close to the midpoint of the scale, with the exception of sentences with weil. In other words, conditionals in general tend to be odd when antecedents are marked by EADVs. While this is an interesting result as far as the German factive and non-factive EADVs are concerned, it suggests that this might not be a useful manipulation for examining the differences between wenn and falls. If we compare Experiment $4 \mathrm{a}$ and $4 \mathrm{~b}$, there is one difference in the design in that in Experiment $4 \mathrm{a}$, the two levels of the NPI factor were manipulated via the absence or the presence of NPIs, whereas the two levels of the EADV factor was manipulated via two different kinds of EADVs, not including a third level without EADVs. This difference is crucial in understanding the results: the wenn/falls contrast was significant in the NPI-absent conditions but not in the NPI-present conditions of Experiment $4 \mathrm{a}$, whereas there

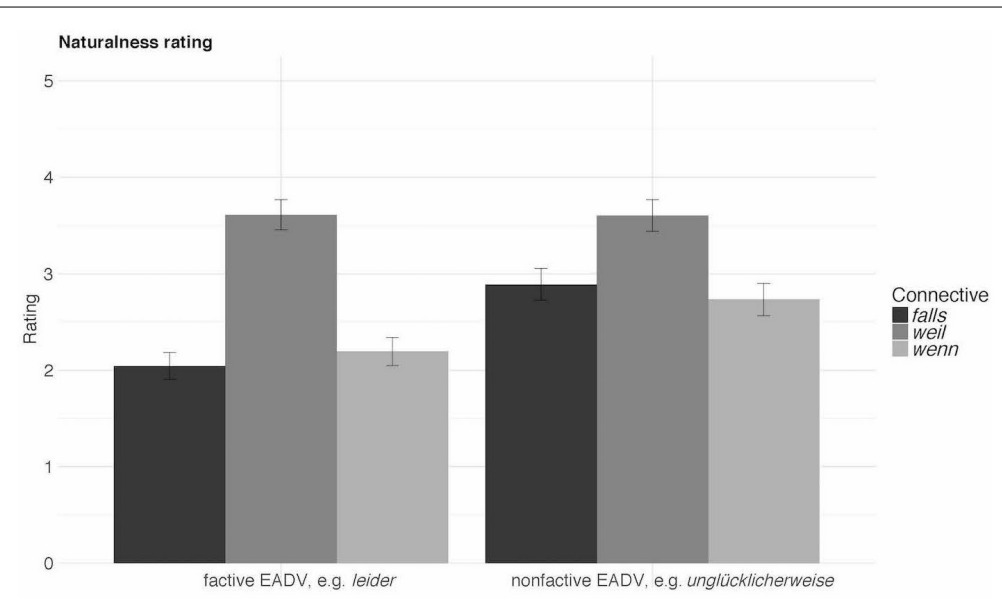

FIGURE 3 | Results of Experiment 4b. 
was no difference between wenn and falls in Experiment 4b, which was potentially due to the lack of a cleaner comparison condition without EADVs.

\section{GENERAL DISCUSSION AND CONCLUSION}

In this paper, I provided distributional properties of the two German CCs wenn and falls and argued that, while they are semantically both non-veridical, they differ in lexical pragmatics in that falls conveys a weaker speaker commitment toward the antecedent proposition than wenn.

In Experiment 1, subjects rated CCs in combination with events in the antecedent with varying degrees of likelihood by common knowledge. The results did not show any effect and thus were unable to confirm the proposed analysis. This might be due to the conversational nature of the meaning difference or due to the use of the binary scale which was not sensitive enough to measure subtle lexical pragmatics. Experiment 2 used the forced lexical choice task. It showed that wenn was preferred over falls in contexts where the protagonist had a high degree of credence in the antecedent proposition, and vice versa in contexts where the protagonist had a low degree of credence in the antecedent proposition. In Experiment 3, the conditional sentences were combined with a RC attached to the conditional antecedent, which conveyed the speaker's high or low degree of credence in the antecedent proposition. Overall, it showed an interaction of RC and CC, with wenn being rated more natural than falls in the belief-condition, and vice versa in the disbelief-condition. This is in line with the proposed wenn/falls contrast and the results of Experiment 2. A closer look at the data revealed further differences due to the used RCs (glauben/nicht glauben vs. un/wahrscheinlich). With the RC containing (nicht) glauben, the experiment shows that the speaker can express positive or negative bias toward the antecedent proposition in the RCs, without causing incoherence with wenn or falls. This means that the lexical contrast between wenn and falls is part of the pragmatic (i.e., non-at-issue) rather than semantic or conventional meaning.

Experiment 4a (Liu, 2019), as summarized above, provides strong evidence for the proposed lexical pragmatic contrast between wenn and falls. Combining it with the results of Experiment 2, I argue that the proposed wenn/falls contrast is real. Experiment $4 \mathrm{~b}$ tested connectives and EADVs in cooccurrence, and shows factive EADVs disprefer non-veridical CCs in comparison to non-factive EADVs. But it did not show a difference between the two CCs. In combination with the results of Experiments 1-3, this means that the wenn/falls contrast is subject to contextual modulations, i.e., it can be more visible in some and less so in others. In general, Experiment $4 \mathrm{~b}$ also provides a first step toward understanding the interaction of co-occurring attitudinal expressions.

While CCs are argued to have no conditional meaning in the restrictor analysis, this paper shows that they can differ in meaning. The current study, in particular Experiment 2 and 3 in combination with the results of Liu (2019), provides evidence that the two frequently used German CCs wenn and falls differ in lexical pragmatics. The non-at-issue meanings of wenn/falls are reinforceable and cancellable, indicating their conversational nature and explaining the contextual effects found in the experiments. I relate their difference to the conveyed doxastic assumptions of the speaker, i.e., they express different degrees of speaker commitment. However, alternative analyses are possible.

One alternative is that the higher degree of speaker commitment in the case of wenn (in comparison to falls) may be due to its ambiguity between conditional and temporal interpretations (and the lack of ambiguity for falls), as temporal adverbial clauses are typically presupposed (Levinson, 1983, among others) and therefore factive. While we have seen examples with clearly conditional, non-temporal meaning, such as the biscuit-conditional in (4), the counterfactual conditional in (7), the conditionals with NPIs in (11) and (40), and the conditionals with EADVs in (12) and (41), we cannot rule out the possibility of the interference by the temporal reading of wenn. In fact, the results of Experiment $4 \mathrm{a}$ and $4 \mathrm{~b}$ are in line with this possibility: in Experiment $4 \mathrm{a}$, the wenn/falls contrast is significant without NPIs, that is, when the temporal interpretation is possible, whereas the difference is not visible with NPIs, i.e., when the temporal interpretation is not possible. In Experiment $4 \mathrm{~b}$, as the temporal reading was not possible across all the conditions, we were not able to detect any difference. However, I do not think this contradicts the current proposal for the wenn/falls contrast in terms of speaker commitment. In fact, Breindl et al. (2014, p. 265f) have argued that the choice of nonambiguous falls leads to an implicature and that, in order to avoid the implicature, the speaker can consciously choose to use wenn, or vice versa, as we see in the examples of (28), possibly with the help of intonation: native speakers confirm that stressed falls strengthens the proposed WUI implicature. To sum up, I think the presence and absence of the temporal reading can be seen as a source (possibly out of several) for the wenn/falls contrast, with the implicature being the consequence in the choice. Here are two independent examples to illustrate the point.

With (13), we presented the difference between the necessity modal verb and the unmodalized variant in that the former triggers a weakened speaker commitment: More committed $<$ unmodalized $\mathrm{p}$, MUST $\mathrm{p}$, POSSIBLY $\mathrm{p}>$ Less committed. It is unclear, however, how the difference arises. But the lexical choice of MUST can lead to the implicature linked to weakened speaker commitment, just as the choice between falls vs. wenn. Similarly, in (45), the speaker can use indicative mood or subjunctive I (Konjunktiv I) mood in the verb. Potts (2005, pp. $186,187)$ argues that German Konjunctiv I is used to indicate the speaker's wish "to distance himself from the propositional content expressed" or that "the speaker is not publicly committed to the truth of $p$," but "It does not indicate that the speaker is committed to the negation of the propositional content in question.”

$$
\begin{aligned}
& \text { Maria sagt, dass sie krank ist/sei. } \\
& \text { Maria says that she sick is/be. } \\
& \text { 'Maria says that she is sick.' }
\end{aligned}
$$


In other words, the choice between ist/sei indicates the degree to which the speaker intends to distance themselves from the given proposition. At the same time, the choice of sei over ist can give rise to an implicature, just as the choice of falls over wenn can. In this regard, it is also worth noting that Elder and Jaszczolt (2016) have put forward the notion of "remoteness from reality" in the context of conditionals. While their point is concerned with conditionals in general, e.g., if (with remoteness from reality, with regard to the antecedent) in comparison to since/when (without remoteness, i.e., alignment with reality), which they attribute to Grice (Elder and Jaszczolt, 2016: 41), the idea may nevertheless be relevant for understanding and modeling the wenn/falls contrast. The choice between them is then a choice between remoteness from or alignment with reality; the choice for falls over wenn can equally lead to an implicature of more focused or increased remoteness. These alternatives provide interesting perspectives that can help us to understand the mechanism behind lexical choices and implicatures, but I also think they are not incompatible with the current proposal.

It is to note, however, that this meaning difference is probably not the only aspect in which the two CCs differ. Consider (46): The sentence can have a conditional reading as in (46b), for which it is fine to replace falls with wenn. But it also has the reading in $(46 \mathrm{~b})$, where falls can be best translated to "(just) in case" in English. The resulting sentence and its interpretation are different from canonical falls-conditionals and it is inappropriate to use wenn. Whether the contrast in terms of speaker commitment plays a role here will be left for future research.

$$
\begin{aligned}
& \text { Falls es regnen sollte, nehme ich einen } \\
& \text { if it rain should, take I an } \\
& \text { Regenschirm mit. } \\
& \text { umbrella with }
\end{aligned}
$$

(a) 'If it should rain, I will take an umbrella with me.'

(b) 'Just in case it should rain, I'm taking an umbrella with me.'

Secondly, falls does not always convey negative doxastic bias but sometimes it can convey negative bouletic bias. For example, in (47), the use of falls is compatible with the speaker's dispreference but incompatible with their preference for the modified event.

$$
\begin{aligned}
& \text { Kauf kein/\# ein Auto. Falls Du unbedingt eins kaufen } \\
& \text { buy no/a car if you definitely one buy } \\
& \text { willst, nimm ein Elektroauto. } \\
& \text { want, take an electric car } \\
& \text { 'Don't buy/Buy a car. If you really want to buy one, take } \\
& \text { an electric car.' }
\end{aligned}
$$

Methodologically speaking, this paper also shows that detection and validation of subtle differences in lexical pragmatics can be methodologically challenging. For example, the forced lexical choice study in Experiment 2 as well as the rating study using the speaker belief judgment task in Experiment 4a (Liu, 2019) show clear positive evidence for the contrast between wenn/falls. However, there was no evidence in the rating study in Experiment 1 and only weaker evidence in the rating study in Experiment 3. It is worth noting again that Experiments 1 and 3 used binary rating scales ${ }^{19}$, and Experiment $4 \mathrm{~b}$ used a 5-point Likert scale, whereas Likert scales with less than 7 points are argued to be problematic (see, e.g., Liddell and Kruschke, 2018). Additionally, since the wenn/falls difference is of the conversational nature and supposed to be nuanced, a higher number of points (e.g., a 10-point scale) might be needed to make the scale sensitive enough to capture the difference, which I leave for future studies. A final note on the limitation of the current study is that the critical items of different numbers were used in combination with other experimental materials, which should be avoided in future to avoid potential confounds. I report experiments with or without evidence here to hopefully help future studies on testing lexical pragmatic differences.

In general, the results in the case study of wenn/falls also call for reconsiderations of Grice's notion of 'implicature' from a probabilistic perspective, e.g., to model lexical pragmatics of near synonyms. We need a more gradable notion of implicature than the conventional and conversational distinction to model lexical semantics and pragmatics. Each case of near-synonyms has its own story in that the distance between them is gradient (cf. experimental evidence) rather than categorical. While this paper does not provide a general integrated theory for this purpose, it showcases the usefulness of speaker commitment scales as a formal tool for modeling lexical pragmatic contrast and the benefits of combining theoretical and experimental perspectives.

\section{DATA AVAILABILITY STATEMENT}

The raw data supporting the conclusions of this article will be made available by the authors, without undue reservation.

\section{ETHICS STATEMENT}

The studies involving human participants were reviewed and approved by the Ethics Committee of Osnabrück University. The patients/participants provided their written informed consent to participate in this study.

\section{AUTHOR CONTRIBUTIONS}

ML conceived and conducted all the reported studies and wrote the manuscript.

\footnotetext{
${ }^{19}$ We used different scales in Experiments 1, 3, and 4 as they were conducted with different sub-experiments together.
} 


\section{FUNDING}

This work has been supported by a grant from the DFG (German Research Foundation) to ML's project “The Semantics and Pragmatics of Conditional Connectives: Cross-linguistic and experimental Perspectives" (project number: 367088975).

\section{ACKNOWLEDGMENTS}

I presented part of the manuscript at the following occasions: Regine Eckardt's Anniversary Workshop at Göttingen (2015), the SPIRIT workshop on Negation at the University of Göttingen (2015), the Department of Philosophy at Peking University (2016), the Linguistic Colloquium at the University of Stuttgart (2016), the annual meeting of XPrag.de at the University of Cologne (2017), the Department of Philosophy at Beijing Normal University (2018), the Linguistics and Philosophy Workshop at the University of Chicago (2018), the Berkeley Germanic Linguistics Roundtable at the University of California Berkeley (2018), the German Department at the University of Cologne (2019), and the Workshop on Concessives vs. Adversatives: Opposing Opposition at the 41th annual meeting

\section{REFERENCES}

Anderson, A. R. (1951). A note on subjunctive and counterfactual conditionals. Analysis 12, 35-38. doi: 10.1093/analys/12.2.35

Arregui, A. C. (2005). On the Accessibility of Possible Worlds: the Role of Tense and Aspect. Ph.D thesis. Amherst, MA: UMass Amherst.

Arregui, A., and Biezma, M. (2016). Discourse rationality and the counterfactuality implicature in backtracking conditionals. Proc. Sinn Und Bedeutung 20, 91-108.

Asher, N. (2000). Truth conditional discourse semantics for parentheticals. J. Semant. 17, 31-50. doi: 10.1093/jos/17.1.31

Baayen, R. H., Davidson, D. J., and Bates, D. M. (2008). Mixed-effects modeling with crossed random effects for subjects and items. J. Mem. Lang. 59, 390-412. doi: 10.1016/j.jml.2007.12.005

Barr, D. J., Levy, R., Scheepers, C., and Tily, H. J. (2013). Random effects structure for confirmatory hypothesis testing: keep it maximal. J. Mem. Lang. 68, 255278. doi: 10.1016/j.jml.2012.11.001

Bates, D. M., Maechler, M., and Bolker, B. (2012). Ime4: Linear Mixed-Effects Models UsingS4 Classes (R Package Version 0.999999-0). Available online at: http://cran. r-project.org/web/packages/lme4/index.html (accessed July 6, 2021).

Bergena, G., and Boskerb, H. R. (2018). Linguistic expectation management in online discourse processing: an investigation of Dutch inderdaad 'indeed' and eigenlijk 'actually'. J. Mem. Lang. 103, 191-209. doi: 10.1016/j.jml.2018. 08.004

Bhatt, R., and Pancheva, R. (2006). "Conditionals," in The Blackwell Companion to Syntax, eds M. Everaert and H. van Riemsdijk (Oxford: Blackwell), 638-687.

Breindl, E., Volodina, A., and Waßner, U. (2014). Handbuch der Deutschen Konnektoren 2: Semantik der Deutschen Satzverknüpfer (= "Schriften des Instituts für Deutsche Sprache 13.1-13.2). Berlin: de Gruyter.

Declerck, R., and Reed, S. (2001). Conditionals: a Comprehensive Empirical Analysis. (Topics in English Linguistics 37.). New York, NY: De Gruyter Mouton.

Dostie, G. (1987). Etude semantique de quatre connecteurs conditionnels: à condition que, pourvu que, en autant que et d'abord que. Fr. Mod. 55LV(3/4), 174-203.

Elder, C.-H., and Jaszczolt, K. M. (2016). Towards a pragmatic category of conditionals. J. Pragmat. 98, 36-53. doi: 10.1016/j.pragma.2016.04.013

Geurts, B. (2019). Communication as commitment sharing: speech acts, implicatures, common ground. Theor. Linguist. 45, 1-30. doi: 10.1515/tl-20190001 of the German Linguistics Society, University of Bremen (2019). Among others, I thank Andreas Blümel, Peter Bosch ( $\dagger)$, Ellen Brandner, Elena Castroviejo, Regine Eckardt, Lyn Frazier, Itamar Francez, Berit Gehrke, Anastasia Giannakidou, Klaus von Heusinger, Stefan Hinterwimmer, Daniel Hole, Fengkui Ju, Chris Kennedy, Manfred Krifka, Laia Mayol, Janina Radó, Stephanie Rotter, Marvin Schmitt, Ming Xiang, and Alan Yu for their feedback on different parts and pieces of the related work. Furthermore, I owe special thanks to Juliane Schwab and Stephanie Rotter for their help with data acquisition as well as her very useful comments on an earlier version of the manuscript, and Matthias Andreß for proofreading the manuscript. Last but not least, I thank all the four reviewers for their invaluable comments; addressing these has really helped me to improve the previous versions. All mistakes are my own, of course.

\section{SUPPLEMENTARY MATERIAL}

The Supplementary Material for this article can be found online at: https://www.frontiersin.org/articles/10.3389/fpsyg. 2021.629177/full\#supplementary-material

Giannakidou, A. (1998). Polarity Sensitivity as (Non)veridical Dependency. Amsterdam-Philadelphia: John Benjamins.

Giannakidou, A. (1999). Affective dependencies. Linguist. Philos. 22, 367-421.

Giannakidou, A. (2011). "Positive polarity items and negative polarity items: variation, licensing, and compositionality," in Semantics: an International Handbook of Natural Language and Meaning, 2nd Edn, eds C. Maienborn, K. von Heusinger, and P. Portner (Berlin: Mouton de Gruyter), 1515-1538.

Giannakidou, A. (2014). "The prospective as nonveridical: polarity items, speaker commitment, and projected truth," in The Black Book. Festschrift for Frans Zwarts, eds D. Gilberts and J. Hoeksema (Groningen: University of Groningen), 101-124.

Giannakidou, A., and Mari, A. (2016). "Epistemic future and epistemic MUST: non-veridicality, evidence and partial knowledge," in Mood, Aspect and Modality Revisited, eds J. Blaszczack, A. Giannakidou, D. Klimek-Jankowska and K.Migdalski (Chicago: University of Chicago Press), 75-118.

Giannakidou, A., and Mari, A. (2021). Truth and Veridicality in Grammar and Thought: Modality, Mood, and Propositional Attitudes. Chicago, IL: University of Chicago Press.

Grice, H. P. (1975). "Logic and conversation," in Syntax and Semantics, Speech Acts, Vol. 3, eds P. Cole and J. L. Morgan (New York, NY: Academic Press), 41-58. doi: 10.1163/9789004368811_003

Grice, H. P. (1989). Studies in the Way of Words. Cambridge, MA: Harvard University Press.

Grosz, P. (2012). On the Grammar of Optative Constructions. Amsterdam: John Benjamins.

Haegeman, L. (2003). Conditional clauses: external and internal syntax. Mind Lang. 18, 317-339. doi: 10.1111/1468-0017.00230

Hoeksema, J. (2012). On the natural history of negative polarity items. Linguist. Anal. 38, 3-34.

Iatridou, S. (1991). Topics in Conditionals. PhD thesis. Cambridge, MA: MIT.

Iatridou, S. (2000). The grammatical ingredients of counterfactuality. Linguist. Inq. 31, 231-270. doi: 10.1162/002438900554352

Ippolito, M., and Su, J. (2014). "Counterfactuals, negation and polarity”, in The Art and Craft of Semantics: a Festschrift for Irene Heim, eds L. Crnic and U. Sauerland (Cambridge, MA: MITWPL), 225-243.

Karttunen, L. (1971). Some observations on factivity. Pap. Linguist. 4, 55-69. doi: 10.1080/08351817109370248

Kratzer, A. (1986). Conditionals. Chic. Linguist. Soc. 22, 1-15. 
Kratzer, A. (1991). "Conditionals," in Semantics: an International Handbook of Contemporary Research, eds A. von Stechow and D. Wunderlich (Berlin: De Gruyter), 651-656

Krifka, M. (2015). Bias in commitment space semantics: declarative questions, negated questions, and question tags. Proc. Semantics Linguist. Theory (SALT) 25, 328-345. doi: 10.3765/salt.v25i0.3078

Krzyżanowska, K. (2019). What is wrong with false-link conditionals? Linguist. Vanguard 5:20190006.

Krzyżanowska, K., Collins, P., and Hanh, U. (2017). Between a conditional's antecedent and its consequent: discourse coherence vs. probabilistic relevance. Cognition 164, 199-205. doi: 10.1016/j.cognition.2017.03.009

Ladusaw, W. (1980). Polarity Sensitivey as Inherent Scope Relations. New York, NY: Garland.

Léard, J.-M. (1987). La syntaxe et la classification des conditionnelles et des concessives. Fr. Mod. 55 LV(3/4), 158-173.

Levinson, S. (1983). Pragmatics. Cambridge, MA: Cambridge University Press.

Liddell, T. M., and Kruschke, J. K. (2018). Analyzing ordinal data with metric models: what could possibly go wrong? J. Exp. Soc. Psychol. 79, 328-348. doi: 10.1016/j.jesp.2018.08.009

Liu, M. (2012). Multidimensional Semantics of Evaluative Adverbs. Boston, MA: Brill.

Liu, M. (2019). The elastic nonveridicality property of indicative conditionals. Linguist. Vanguard 5:20190007.

Liu, M., and Barthel, M. (2021). Semantic Processing of Conditional ConnectivesGerman Wenn 'if' vs. Nur Wenn 'Only If'. Unpublished manuscript, Humboldt University of Berlin.

Liu, M., König, P., and Mueller, J. L. (2019). Novel ERP evidence for processing differences between negative and positive polarity items in German. Front. Psychol. 10:376. doi: 10.3389/fpsyg.2019.00376

Liu, M., and Wang, Y. (2021). "Speaker commitment by Mandarin conditional connectives: distributional and experimental evidence," in Proceedings of the 21th Chinese Lexical Semantics Workshop (CLSW2020). In Springer's Lecture Notes in Computer Science, (Hong Kong: University of Hong Kong).

Liu, M., Rotter, S., and Giannakidou, A. (2021). Bias and Modality in Conditionals: Experimental Evidence and Theoretical Implications. Unpublished manuscript, Humboldt University of Berlin.

Lyons, J. (1977). Semantics. Cambridge, MA: Cambridge University Press.

Montoliìo, E. (2000). "On affirmative and negative complex conditional connectives," in Cause, Condition, Concession, Contrast, eds E. Couper-Kuhlen and B. Kortmenn (New York, NY: Mouton de Gruyter), 143-171. doi: 10.1515/ 9783110219043-007

Potts, C. (2005). The Logic of Conventional Implicatures. Oxford: Oxford University Press.

R Core Team (2018). R: A Language and Environment for Statistical Computing. Foundation for Statistical Computing, Vienna, Austria. Available online at: https://www.R-project.org

Reis, M., and Wöllstein, A. (2010). Zur Grammatik (vor allem) konditionaler V1-Gefüge im Deutschen. Z. Sprachwiss. 29, 111-179.

Schwenter, S. (2001). Expectations and (in)sufficiency: Spanish como conditionals. Linguistics 39, 733-760.

Simons, M., Tonhauser, T., Beaver, D., and Roberts, R. (2010). "What projects and why," in Proceedings of the Semantics and Linguistic Theory (SALT), Vol. 21, (Ithaca, NY: CLC Publications), 309-327. doi: 10.3765/salt.v0i20.2584
Skovgaard-Olsen, N., Singmann, H., and Klauer, K. C. (2016). The relevance effect and conditionals. Cognition 150, 26-36. doi: 10.1016/j.cognition.2015. 12.017

Sode, F., and Sugawara, A. (2019). "On the deliberative use of the German modal sollte," in New Frontiers in Artificial Intelligence. JSAI-isAI 2018, LNCS 11717, eds K. Kojima, M. Sakamoto, K. Mineshima, and K. Satoh (Cham: Springer), 341-356. doi: 10.1007/978-3-030-31605-1_25

Starr, W. (2019). Counterfactuals. Available online at: https://plato.stanford.edu/ entries/counterfactuals/ (accessed July 6, 2021).

Tonhauser, J. (2012). Diagnosing (not-)at-issue content. Proc. Semant. Represent. Lang. Am. 6, 239-254.

Visconti, J. (1996). On English and Italian complex conditional connectives: matching features and implicatures in defining semanto-pragmatic equivalence. Lang. Sci. 18, 549-573. doi: 10.1016/0388-0001(96)00034-4

Volodina, A. (2006). "Wenn-relationen: schnittstelle Zwischen syntax, semantik und pragmatik," in Grammatische Untersuchungen, Analysen und Reflexionen. Festschrift für Gisela Zifonun, eds E. Breindl, L. Gunkel, and B. Strecker (Tübingen: Narr), 359-379.

Volodina, A. (2011). Konditionalität und Kausalität im Diskurs. Eine korpuslinguistische Studie zum Einfluss von Syntax und Prosodie auf die Interpretation komplexer Äußerungen. Tübingen: Narr.

von Fintel, K. (2007). If: The Biggest Little Word. Available online at: http://mit.edu/ fintel/gurt-slides.pdf (accessed July 6, 2021).

von Fintel, K. (1999). NPI licensing, strawson entailment, and context dependency. J. Semant. 16, 97-148. doi: 10.1093/jos/16.2.97

von Fintel, K. (2011). "Conditionals," in Semantics: an International Handbook of Natural Language and Meaning, eds C. Maienborn, K. von Heusinger, and P. Portner (Berlin: de Gruyter), 1515-1538.

Zaefferer, D. (1991). "Conditionals and unconditionals: cross-linguistic and logical aspects," in Semantic Universals and Universal Semantics, ed. D. Zaefferer (Dordrecht: Foris), 210-236. doi: 10.1515/97831108705 27-011

Zakkou, J. (2018). The cancellability test for conversational implicatures. Philos. Compass 93/3:e12552.

Zimmermann, M. (2004). Zum "Wohl": Diskurspartikeln als Satztypmodifikatoren. Linguist. Ber. 199, 1-35.

Conflict of Interest: The author declares that the research was conducted in the absence of any commercial or financial relationships that could be construed as a potential conflict of interest.

Publisher's Note: All claims expressed in this article are solely those of the authors and do not necessarily represent those of their affiliated organizations, or those of the publisher, the editors and the reviewers. Any product that may be evaluated in this article, or claim that may be made by its manufacturer, is not guaranteed or endorsed by the publisher.

Copyright (c) $2021 \mathrm{Liu}$. This is an open-access article distributed under the terms of the Creative Commons Attribution License (CC BY). The use, distribution or reproduction in other forums is permitted, provided the original author(s) and the copyright owner(s) are credited and that the original publication in this journal is cited, in accordance with accepted academic practice. No use, distribution or reproduction is permitted which does not comply with these terms. 